\title{
A RELATIONAL THEORY OF DEFAULT RULES FOR COMMERCIAL CONTRACTS
}

\author{
ROBERT E. SCOTT*
}

\begin{abstract}
$\mathrm{T}$ HE relationship between legal rules and the strategies that commercial parties use to deal with risk is among the most important and least understood topics in law and economics. Organizational theorists have generally confined their analyses to the nature of the firm and other permanent relationships. ${ }^{1}$ Academic commercial lawyers, in turn, have been far less venturesome than their corporate colleagues in applying fundamental economic insights. Not surprisingly, therefore, we know very little about the inner workings of most commercial relationships. For these reasons (and more) I applaud efforts to integrate economic insights and legal structures, exemplified by Clay Gillette's imaginative essay on the nature of commercial relationships. ${ }^{2}$

Gillette makes two independent claims in his article. The first concerns how commercial parties deal with risk. The second concerns how we, as independent observers, can ferret out the strategies that these parties have pursued toward risk in individual cases. His second claim is potentially the more important. Although Gillette is cautious to note the limits of his project, he argues that the structural relationship between the parties provides a rich source of information that enhances our ability to predict the type of contractual terms that the parties would have chosen to govern their affairs when certain remote or unanticipated contingencies

Lewis F. Powell, Jr., Professor and Member, Center for Advanced Studies, University of Virginia.

${ }^{1}$ The few studies of contractual alternatives for the firm are marred by simplistic assumptions about the relevant legal rules. See, for example, James A. Brickley \& Frederick H. Dark, The Choice of Organizational Form: The Case of Franchising, $18 \mathrm{~J}$. Fin. Econ. 401 (1987); Tracy R. Lewis, Reputation and Contractual Performance in Long-Term Projects, 17 Rand J. Econ. 141 (1986).

${ }^{2}$ Clay Gillette, Commercial Relationships and the Selection of Default Rules for Remote Risks, in this issue.
\end{abstract}

[Journal of Legal Studies, vol. XIX (June 1990)]

(C) 1990 by The University of Chicago. All rights reserved. 0047-2530/90/1902-0019\$01.50 
occur. This perspective, which Gillette develops in some detail, provides additional support for resorting to hypothetical bargain analysis to supply the relevant default terms by rendering it more plausible that these particular parties would have chosen this default rule if required to bargain explicitly in advance.

Gillette's method of analysis would constitute a genuine theoretical advance if it allowed legal academics and policymakers to make more refined predictions about the outcome of hypothetical bargains among commercial actors. Yet while his transaction approach yields important insights about particular contracting strategies, paradoxically, Gillette is ultimately unable to generalize about risk-allocation strategies or about the choice of default rules that best implements his desired goals. Unhappily, Gillette is disabled from making any generalizations (at least with any degree of confidence) by the internal logic of his very complex model of how parties deal with risk. Moreover, Gillette's dilemma is not an isolated phenomenon. Other commentators, most notably Jules Coleman, Douglas Heckathorn, and Steven Maser ${ }^{3}$ and Ian Ayres and Robert Gertner, ${ }^{4}$ have recently advanced additional normative arguments in support of more complex and particularized default rules for commercial contracts. Taken together, these arguments challenge both the wisdom and the efficiency of the existing stock of generalized default rules used by courts and legislatures to fill gaps in incomplete contracts.

For students of contracts and commercial law, these challenges are revolutionary. The principal task of the law of commercial contracts is to set default rules for commercial actors and other repeat players who, presumably, are quite capable of bargaining for customized alternatives. The conventional assumption, therefore, is that in such commercial environments it is more important for the law to be certain than to be right. ${ }^{5}$ The argument for more complex and particularized default rules thus undermines a traditional premise of commercial law.

Although the participants in the debate over default rules adopt radically different approaches, they all grapple with what appear to be fundamental contradictions between legal theory and reality. Thus, for example, bargaining theory suggests that filling gaps in incomplete contracts is a complex undertaking. Optimal default rules must be sensitive to the

${ }^{3}$ Jules Coleman, Douglas Heckathorn, \& Steven Maser, A Bargaining Theory Approach to Default Provisions and Disclosure Rules in Contract Law, 12 Harv. J. Law \& Pub. Pol. 639 (1989).

${ }^{4}$ Ian Ayres \& Robert Gertner, Filling Gaps in Incomplete Contracts: An Economic Theory of Default Rules, 90 Yale L. J. 87 (1990).

${ }^{5}$ Alan Schwartz \& Robert E. Scott, Commercial Transactions: Principles and Policies 569-71 (1982). 
contracting environment and to the nature of the particular contractual relationship. ${ }^{6}$ Yet, the overwhelming majority of implied contract terms are simple and categorical. Furthermore, theory suggests that rational commercial actors would prefer default rules that maximize the joint benefits from contracting. ${ }^{7}$ But the general rules of contract are framed instead as simple winner-take-all, binary risk allocations. Finally, theory tells us that, in filling gaps in contracts, the law should devise strategies that replicate the agreement the particular disputants would have specified. ${ }^{8}$ To the contrary, however, contractual default rules are largely insensitive to the nuances of particular settings.

Given these contradictions, it is not surprising that a number of theorists have concluded that conventional approaches to formulating default rules are inadequate. Indeed, several years ago, these concerns led me to argue for "more specialized preformulated rules for particular varieties of relational contracts." ${ }^{\prime 9}$ Each of these critical analyses (including my own) have adopted a common approach to the problem of inadequate default rules. They first develop a conceptual model with a clear normative perspective. Thereafter, they examine whether the legal rules reflect or deviate from the stated norm. While these normative perspectives are (collectively) insightful, they also tend to overlook rationalizing factors that may explain the legal outcomes. In this article, I adopt an alternative approach. My aim is to develop a normatively plausible, positive theory of contractual gap fillers. My purpose, then, is to both explain and justify the law's preference for generalized or "off-the-rack" default rules in commercial contracts.

In Section I of this article, I argue that complex risk-allocation models are inconsistent in important respects with the assumption that commercial actors are rational utility maximizers. I suggest instead that rational commercial actors are motivated by a dominant strategy of cooperative risk reduction. In Section II, I use the cooperative approach to risk allocation in order to develop criteria for selecting optimal default rules. Fi-

${ }^{6}$ See, for example, Coleman, Heckathorn, \& Maser, supra note 3, at 708 ("Failing to attend to specific contextual features of disputes in the name of reconstruction-makes a mockery of the idea of the ex ante contract as a default rule'); Gillette, supra note 2, at 44 ("the appropriate model . . . is far more complex than much of the writing to date indicates"); Ayres \& Gertner, supra note 4, at 128-29 ("Lawmakers need to consider explicitly the informational as well as the contractual equilibria generated by alternative default rules"').

7 See Charles J. Goetz \& Robert E. Scott, Principles of Relational Contracts, 67 Va. L. Rev. 1089, 1095-99 (1981).

${ }^{8}$ Coleman, Heckathorn, \& Maser, supra note 3, at 707-9; Gillette, supra note 2.

9 Charles J. Goetz \& Robert E. Scott, The Mitigation Principle: Toward a General Theory of Contractual Obligation, 69 Va. L. Rev. 967, 1024 (1983). 
nally, in Section III, I confront an apparent paradox: an egoistic model (though normatively implausible) best explains the default rules now in use in commercial law. I resolve that paradox by proposing a relational theory of commercial law: under this approach the pervasive use of binary default rules in commercial contracting results from the intersection of two forces. First, on the legal side, the current enforcement mechanisms are necessarily crude and inexact and are likely to remain that way. Second, in response to the weakness of the rules of legal enforcement, powerful social pressures arise to encourage the enforcement of commercial undertakings. The proper choice of default rules depends, therefore, not only on the internal operation of the legal system but also on the linkages between the legal system and the norms of social enforcement that are too often ignored. Understanding how these different systems operate together in the context of long-term commercial contracts thus offers both a positive explanation and a normative justification for the existing scheme of commercial-law default rules.

\section{A Cooperative Model of Commercial Contracting Behavior}

Any theory of optimal default rules for commercial contracts must rest on a plausible model of the risk-allocation strategies pursued by commercial parties. In his article, Gillette claims that commercial parties' approach to risk can be understood as falling along a continuum, ranging from an overriding preference for wagers and other zero-sum games (which Gillette calls egoism) to a polar preference for cooperative risk sharing. Gillette uses the supposed dichotomy between egoism and cooperation to demonstrate that a legally implied default rule requiring mutual adjustment and cooperation may be inconsistent with the ex ante contractual interest of many commercial parties. ${ }^{10}$ But in exploring particularized risk-allocation strategies, Gillette discovers that the entire edifice of generalized rules begins to crumble. Not only are risk-allocation strategies influenced by individual risk preferences, but they also may be affected by cognitive biases and other distortions. He concludes, therefore, that the appropriate model for filling gaps in incomplete contracts is far more complex than previous writings have acknowledged.

Gillette's pessimism about the efficacy of generalized default rules is not an isolated reaction. A similar conclusion is reached by Ayres and Gertner and by Coleman, Heckathorn, \& Maser although each proceeds from vastly different premises. ${ }^{11}$ Each of these arguments for more partic-

${ }^{10}$ Gillette, supra note 2.

11 Ayres and Gertner argue that to implement a complete theory of default choice requires courts to pay attention to $(a)$ what the parties want, $(b)$ whether they are likely to obtain that, 
ularized default rules is driven by the claim that individual attitudes toward risk influence the nature of particular contractual relationships in systematic and predictable ways. Gillette assumes, for example, that a substantial number of commercial actors enter into binding, long-term executory contracts in order to engage in zero-sum wages on the outcome of uncertain future events. For these parties, a subsequent legal interpretation of their contract should never impose a cooperative solution (if the parties' risk attitudes were properly understood). Rather, both parties would prefer that all unspecified contingencies be assigned in a winnertake-all, binary fashion. In this way, commercial egoists can maximize the variance between gains and losses. ${ }^{12}$

Under Gillette's scheme, egoistic contractors form one pole of a bargaining continuum. At the opposite pole are cooperative bargainers who enter into commercial contracts with mutual adjustment and risk sharing as their dominating preferences. Gillette suggests that these attitudes derive from the cooperators' belief that they are more likely to be rescued than to rescue. The cooperators prefer legal default rules that promote cooperative risk sharing of unspecified risks. ${ }^{13}$

Quite clearly, since these two cases are modeled as polar extremes, most commercial parties will fall somewhere along the continuum. Nevertheless, for the egoistic model (or any other particularized strategy) to be a useful method for prescribing generalized legal rules, it must describe the risk strategies of a significant set of rational commercial actors. I suggest, to the contrary, that the egoist and the cooperator (or any other

and $(c)$ the costs associated with obtaining or not obtaining their objectives. Furthermore, they claim, it will be especially important for courts to distinguish the reasons why gaps were left in any particular contract. Thus, they anticipate that a court, armed with the appropriate concern for gap filling, will have to estimate both the transitional and the strategic barriers to contracting around particular default rules, as well as having to understand the cost associated with failing to strike the efficient contract. See Ayres \& Gertner, supra note 4 , at $106-7$.

While Gillette and Ayres and Gertner are concerned with the efficiency properties of the optimal default rules, Coleman, Heckathorn, and Maser reach similar conclusions by searching for the underlying moral justification for imposing default outcomes in incomplete contracts. They suggest that, "in all cases, satisfying the demands of rationality in a contract are considerably more complex than the hand-waving response of the legal economistnamely, to find an allocation of rights and responsibilities that is jointly wealth maximizing would suggest" (Coleman, Heckathorn, \& Maser, supra note 3, at 707). Coleman et al. argue that it is inappropriate for courts to impose jointly maximizing outcomes on parties without regard to whether the distribution of gains and losses is also jointly rational. They conclude, therefore, that a minimum condition for justifiably imposing any default rule is that it imposes obligations on the parties that would have been rational for them to agree on in the circumstances of their contract.

12 Gillette, supra note 2.

${ }^{13} I d$. 
party pursuing a particularized strategy) are not useful models for understanding how the law should facilitate commercial contracting behavior. If we assume rationality, then it follows that, regardless of the risk attitudes of particular parties, the dominant strategy for contractual risk allocation is to maximize the expected value of the contract for both parties. Only by allocating risks in order to maximize the joint expected benefits from their contractual relationship can the parties hope to maximize their individual utility. Any deviation from joint maximization generates an inefficient and thus an unstable contract. This joint maximization objective cannot be fully realized if contracting parties systematically indulge their individual taste for wagering or altruism or, alternatively, engage in strategic maneuvering over vexing distributional issues.

To illustrate the dominating effect of the joint maximization impulse on parties to long-term commercial contracts, recall the familiar case of $\mathrm{Al}$ coa v. Essex. ${ }^{14}$ The contract between Alcoa and Essex required Essex to purchase up to 40 million pounds of aluminum per year for twenty years from Alcoa. The contract price was adjusted by a complex escalator clause that was principally tied to the wholesale price index. Subsequently, the drastic increase in fuel prices following the oil embargo and related events in 1973 caused Alcoa's production costs to rise twice as fast as the index. Thus, by 1979 Essex was receiving aluminum from Alcoa at thirty-six cents per pound and reselling it on the open market at seventy-three cents per pound. ${ }^{15}$ Using a theory of mutual mistake, the court imposed a risk-sharing solution on the ground that the agreed-on escalator provision did not anticipate the exogenous shock on production costs.

Put aside for the moment the issue of whether the court-imposed adjustment was the appropriate default rule, and consider the contractual strategies of Alcoa and Essex. Initially, we must clarify the distinction between individual and institutional behavior. For example, in his model Gillette seems to focus on the risk attitudes of individual managers because he believes that firms will be unable to monitor managers sufficiently to forestall deviations from the firms' desired goal of risk neutrality. The claim that default rules for commercial contracts should be tailored to the risk attitudes of individual managers seems self-evidently problematic. ${ }^{16}$

14 Aluminum Co. of America v. Essex Group, Inc., 499 F. Supp. 53 (W.D. Pa. 1980).

15 See Victor P. Goldberg, Price Adjustment in Long-Term Contracts, 1985 Wis. L. Rev. $527,534-40$, for a synthesis of facts derived from the published decision and the briefs.

${ }^{16}$ Since investors can achieve a desired level of risk by diversifying their portfolio, they want each firm in the portfolio to maximize share value. If managers seek to satisfy these investor preferences and maximize share value, they must act in a risk-neutral manner. 
But even assuming that contracting strategies are assessed in terms of the risk attitudes of individuals, the contractual agreement between Alcoa and Essex would not be systematically influenced by variations in risk attitudes. These attitudes are overwhelmed by the dominating effects of risk-allocation strategies that successfully reduce risks and thus generate mutual gains from the contract.

Assume first that Alcoa and Essex are Gillette's egoists. As egoists, Alcoa and Essex (or their individual bargaining representatives) may be tempted to satisfy individual preferences for wagering on low-probability exogenous events such as quarantines and embargoes. But rationality tells us that, even as egoists, the parties' first goal will be to allocate endogenous risks. These are contingencies that require decisions about storing inventory, opening mines, or building structures-events over which one party or the other has some control. It is this activity that will maximize the expected value of the contract. For these contingencies, a probability distribution over the possible "states of nature" is known-or the parties decide to act as if it were known. It is logical, therefore, to ask first how commercial egoists might distribute the risk of such "foreseeable" contingencies. With respect to certain of these known risks, the parties can by contract reduce the amount of risk each faces. When such actions are cost justified, there is a potential utility gain to both parties from adopting a binary strategy of risk control: assign the entire risk of such contingencies to the party best able to reduce the amount of the risk. ${ }^{17}$

At first glance, then, when Alcoa and Essex initially pursue a riskcontrol strategy, they appear to be making winner-take-all gambles on the future. However, a fundamental shift occurs once the egoists lock into a long-term relationship. Now, the parties will face new problems as time passes and conditions change. Inevitably, some contingencies become more or less probable, while others that were previously beyond calculation fall under one or the other's influence. Consequently, the initial allocation of endogenous risks no longer represents the party's best response

\footnotetext{
Thus, firms have strong incentives to motivate their individual managers to behave risk neutrally. If this is so, then commercial firms would, other things being equal, prefer default rules premised on risk neutrality. A default rule premised on a strategy of risk aversion or risk preference will reduce the firm's profits. If the firm's goal is to maximize profits, it would prefer individual managers to act as if they were risk neutral. (See Alan Schwartz, The Continuing Puzzle of Secured Debt, 37 Vand. L. Rev. 1051, 1062-65 (1984).) There is some evidence that firms structure managers' financial rewards in order to control risk biases. (See W. Roberts, Increasing Bank Profitability by Modifying Loan Officer Performance, 65 J. Com. Bank Lending 2 (1983).)

17 This analysis of risk-control strategies builds on the discussion in Robert E. Scott, Conflict and Cooperation in Long-Term Contracts, 75 Calif. L. Rev. 2005, 2012-18 (1987).
} 
to future contingencies. It is important to recall that the parties have not thus far dealt with exogenous events at all. Rather, the passage of time makes their initial risk-reduction strategy dealing with endogenous risks inefficient.

Thus, there are mutual gains for both if the parties can agree to adjust the initial contract terms to accommodate subsequent events. Will they do so? Obviously, ex post, neither party has any interest in voluntarily adjusting the contract to reduce the other's excess costs. ${ }^{18}$ But, viewed ex ante, if either party anticipates bearing excess cost, it will negotiate for more favorable price terms to compensate for these additional costs. In so doing, they necessarily reduce the expected value of the contract for the other. Therefore, assuming perfect legal enforcement, even pure egoists will find it in their rational self-interest to agree to adjust their initial risk assignments in order to reduce expected future costs. The resulting agreement might take the form of a "good-faith adjustment," "gross inequities," or some other renegotiation clause. ${ }^{19}$ But, in whatever guise, the parties will be motivated to promote cooperative risk reduction because it is in each party's self-interest to do so.

Let me emphasize that this motivation to adjust cooperatively will not necessarily produce a renegotiation clause. A clause that requires cooperative adjustment or renegotiation creates additional problems that also must be evaluated when the initial contract is negotiated. ${ }^{20}$ But, in any case, the motivation to adjust the contract is not altruism, nor is it based on the prediction that one party is more likely to be rescued than the other. It is merely the optimal (that is, rational) response to each party's desire to maximize its individual utility.

But how might the parties deal with exogenous events (such as the risk of flood or earthquake) after they have finished assigning endogenous risks? It is conceivable, of course, that, since Alcoa and Essex have an assumed taste for gambling, they will link their risk-reduction package to a series of wagers about the uncertain future. But it would be irrational to

${ }^{18}$ Assume, for example, that Alcoa's production costs increase unexpectedly after 90 percent of the contract aluminum has been produced. Assume further that, if the parties could agree to adjust the initial contract quantity, they would thereby reduce the joint costs of contracting. But short-term considerations will now affect each party's calculations. Unless renegotiation would be mutually advantageous, Essex has no interest in reducing Alcoa's costs and also has little incentive to convey helpful information that might facilitate a readjustment.

19 These clauses may have various designations, including "good-faith adjustment," "gross inequities," and "market reopener," but casual empiricism confirms their prevalence in long-term contracts. See Wolfgang Peter, Arbitration and Renegotiation of International Investment Agreements 154-5 (1986).

${ }^{20}$ See Section IIC infra. 
do so if the resulting winner-take-all contract impairs the expected benefits from risk reduction. At a minimum, the parties would have to compare the cost of indulging in such wagers against alternatives such as betting on sports events, trips to Las Vegas, and the like. Whatever their idiosyncratic preferences, few would argue that individual tastes should be subsidized by a legal default rule that imposes noncooperative solutions. (At best, the law might permit egoistic bargainers who have idiosyncratic preferences for wagering to signal their preferences through specially designed contract terms.)

In sum, the dichotomy between egoism and cooperation is false. All commercial parties are egoistic in that they pursue individual self-interest. All parties are also cooperators in that they prefer mutual adjustment because it enhances the expected value of the contract for each. Commercial parties will commit to cooperative strategies, therefore, whenever the expected benefits from risk reduction exceed the expected costs of enforcing the agreement. Winner-take-all allocations of exogenous risk are not merely gambles on unknown events; they also necessarily impair the parties' ability to respond fully to known contingencies. The instinct to distinguish between egoism and cooperation results from an understandable confusion between ex ante and ex post strategies. Contracting parties agree (explicitly or implicitly) to cooperate in the future, not because of altruism, but because it lowers the ex ante contract price by more than the cost of cooperation. The gravamen of disputes over failures to cooperate is not that the defendant has acted entirely out of self-interest but that the defendant has done so when it has been paid in advance to cooperate. ${ }^{21}$

In sum, a premise of rationality strongly suggests that the dominating motivation of commercial contractors is to induce cooperative risk reduction. Furthermore, this generalization is not impaired by the argument that parties will modify their cooperative objectives in order to take account of individual preferences for distribution. ${ }^{22}$ The task, after all, is not to define the entire contract for the parties, but merely to set the default rules against which particular bargainers can thereafter design customized alternatives. The distributional arrangements between the parties will

\footnotetext{
${ }^{21}$ In the current version of his paper, Gillette, supra note 2, endorses the proposition that cooperative strategies under contract derive from self-interest. His arguments are now more clearly designed to ask the question of how the initial endowments of egoists influence the way their self-interests are manifested. Thus, the strong distinction that he draws between egoists and cooperators may reflect more rhetorical than substantive differences between our positions. Indeed, both of us would approach legal responses to the problem of strategic behavior in much the same way. See Section IIC infra.

${ }^{22}$ The distributional argument is advanced by Coleman, Heckathorn, \& Maser, supra note 3 .
} 
necessarily be particularized and idiosyncratic and thus in all cases will require individualized alternatives. Furthermore, the norm of cooperation is not impaired because contracting parties often negotiate under conditions of asymmetrical information in which one party is reluctant to reveal key information to the other. ${ }^{23}$ Legitimate concern for minimizing information barriers may alter the shape of particular default rules, but it does not affect the central claim that in all cases the parties are motivated by a desire to maximize the joint benefits of the contractual venture.

A general norm of mutual cooperation does not, however, imply that courts should require renegotiation or cooperative adjustment by individual parties. On the contrary, the default rules of contract law reveal a clear preference for the alternative: clear, categorical assignments of risk. The cooperative norm merely provides a starting point: a strategic objective with which to begin the more complex task of specifying the default rules that best facilitate the parties' contractual goals.

\section{Criteria for Selecting Optimal Default Rules}

The central task for the law of commercial contracts is to fill gaps in incomplete contracts. I suggested earlier that a simple norm of cooperative risk reduction best explains the dominant risk-allocation strategy of rational commercial contractors. But the task of specifying which default rule best implements that goal is more complex than it first appears. Before the cooperative approach can confidently be embraced as the dominant paradigm, several vexing questions must be addressed. First, is it justifiable to select default rules that satisfy the preferences of the majority of rational commercial actors when those rules conflict with the apparent strategies of particular litigants? Second, assuming majoritarian default rules are justified in principle, what criteria determine their content in particular cases?

\section{A. Majoritarian versus Individualized Default Rules}

The common-law approach to devising default rules for unspecified risks is best captured in Justice Cardozo's justly famed dictum: "[I]ntention not otherwise revealed may be presumed to hold in contemplation the reasonable and the probable." ${ }^{24}$ This premise requires the policymaker (or judge) to perform a mental experiment: how would rational actors similarly situated have bargained over this question in advance? But this conceptualization blurs two distinct views of rationality

${ }^{23}$ See Ayres \& Gertner, supra note 4.

24 Jacob \& Youngs v. Kent, 230 N.Y. 239, 242, 129 N.E. 887 (1921). 
that may be deployed to fill in the contractual gaps, one of subjective and the other of objective rationality. Unhappily, these views frequently lead to different outcomes in particular cases. Thus, if the social goal is to replicate the bargain that would have been struck by the parties to this dispute, then subjective rationality requires that the particular circumstances and preferences of the parties be taken into account, much as Gillette seeks to tailor different rules for egoists and cooperators. ${ }^{25}$ Alternatively, default rules can also be measured by objective rationality; that is, whether the rule appropriately regulates the conduct of other parties likely to have similar disputes in the future. Under the objective conception of rationality, the question is what risk allocation the majority of similarly situated rational actors would have devised were they to bargain costlessly over the question in advance. Objective rationality derives from a norm of expanded choice. Majoritarian default rules expand contractors' choices by providing widely suitable preformulations, thus eliminating the cost (and the error) of negotiating every detail of the proposed agreement. ${ }^{26}$ The objective conception of rationality undercuts the relevance of particular characteristics of particular bargainers. Indeed, this determinedly instrumental approach reinforces the claim that particular characteristics or preferences for risk ought not to affect the specifications of default rules.

Can these two widely divergent conceptions of rationality be reconciled? The expanded-choice norm supplies an argument that, at least in theory, supports the objective or majoritarian approach. A presumption of "neutrality" is a necessary corollary to any conception of expanded choice; the state has no desire to impose its default rules on unwilling parties. Viewed ex ante, therefore, individual parties lose nothing from the specification of majoritarian default rules since they remain unrestrained from designing customized alternatives to replace the statesupplied terms. Thus conceived, the underlying objective of contract law is to develop both preformulated (that is, generalized) default rules and a menu of customized alternatives, which, taken together, reduce the cost of contracting for both typical and atypical bargainers. The arguments for individualized or subjectively defined default rules reflect an incomplete understanding of the systematic functions of contract law. So long as the

\footnotetext{
${ }^{25}$ Under the subjective approach, the default rule is justified because it specifies the outcome that would have been most rational for these particular disputants. The most rational outcome supplies indirect evidence of what these parties would have agreed to. In turn, this provides a normative basis for imposing those terms ex post.

${ }^{26}$ See Charles J. Goetz \& Robert E. Scott, The Limits of Expanded Choice: An Analysis of the Interactions between Express and Implied Contract Terms, 73 Calif. L. Rev. 261, 265-67 (1985).
} 
law invites atypical parties to opt out, the state should select default rules that best serve the needs of the broadest number of future bargainers. The inherent tension between majoritarian and individualized default rules arises from the mistaken effort to collapse the two parts of contractual formation-generalization and particularization-into one.

\section{B. Designing Optimal Default Rules}

What form, then, should the objective default rules take? Here there are several guidelines to consider.

The Institutional Bias against Contracting Out. The first norm in dealing with contracting out is cautionary. Under the neutrality principle, the state should attach no presumptive moral weight to its chosen default terms. Its job is supplementation, not dictation. Since particular parties have better information about their own situation than the state, they should be allowed to reject at will the majority norm. Accordingly, there should be no implicit legislative or judicial limitation on contracting out.

This principle, however, is often undercut by courts that tend to treat state-created default rules as presumptively "fair." This mistaken effort unfortunately leads to judicial disapproval of efforts to vary the general default rules by particularized agreement. Courts are more likely to misinterpret any agreement that attempts to combine individually negotiated provisions with customarily implied legal rules. For example, in Publicker Industries $v$. Union Carbide Corp. ${ }^{27}$ the parties agreed to a price term with an escalation clause that provided: "[I]n no event . . . shall the ... increase in the contract price . . . exceed the price listed below." The parties apparently believed that the escalator merely supplemented the standard implied term that performance would be excused entirely if adversely affected by unforeseeable circumstances. The court, however, mistakenly interpreted this effort as an attempt to countermand the contractual doctrine of excuse altogether. As a consequence, when the priceadjustment escalator failed to work properly, the court imposed on the performing party the risk of unforeseeable price increases up to the contractually specified limitation. ${ }^{28}$

2717 U.C.C. Rep. Serv. 989, 992 (E.D. Pa. 1975); see also Mo. Pub. Serv. Co. v. Peabody Coal Co., 583 S.W.2d 721, 728 (Mo. App. 1979) (seller's claim for excuse denied because seller "agreed to the use of the Industrial Commodities Index").

${ }^{28}$ The converse error may occur as well. Terms intended to allow parties to contract out of a prevailing norm may be interpreted as merely expressing the norm. See Brunswick Box Co. v. Coutinho Caro \& Co., 617 F.2d 355 (4th Cir. 1980) (surrounding context used to override the standard meaning of F.A.S. term); Modine Mfg. Co. v. North East Independent School Dist., 503 S.W.2d 833, 837-38 (Tex. Civ. App. 1973) (trade usage shows that express term "capacities shall not be less than indicated" should be interpreted as permitting "reasonable" variations). 
These uncertainties impede experimentation with innovative methods for allocating commercial risks. Contracting parties are likely to encounter substantial problems when they attempt to develop innovative or particularized agreements for distributing risks. In the first place, they may have difficulty escaping the standardized default rules since any interpretive disagreements are likely to arise in the very same contexts that the particularized contractors have sought to escape. As a consequence, the state's institutional support for the existing set of default rules results in an unfortunate bias against unconventional risk assignments.

That bias might be reinforced, moreover, if the state thinks that there is some public interest in having a uniform set of contractual provisions for all transactions within a given group or class. So long as commercial transactions are discrete, it is not necessary for innovative parties to coordinate their behavior with parties who prefer to follow the conventional norms. Similarly, it is mistaken to think that the recognition of individualized terms necessarily undermines the desired clarity of off-therack default provisions. The state can require those parties who do want to individualize their agreements to give clear signals that they have contracted out of the standard default provision. ${ }^{29} \mathrm{~A}$ body of interpretive law can then evolve to explicate not only the standard default provisions of the codes and the common law but also the privately generated alternatives voluntarily adopted by a substantial, if minority, fraction of the commercial population. So long as both courts and parties can identify those occasions where individualization has taken place, then judicial decisions on atypical contracts should not undercut the authority of the standard default norms that govern in cases of contractual silence. Contractual innovation and experimentation is surely facilitated by allowing persons to adopt with confidence contractual alternatives that they find superior to the default provisions. There is a clear social need to foster both contractual regimes.

Information-Forcing Default Rules. Certain default rules are set, not because they represent the ultimate allocations preferred by most bargainers, but rather because they are best suited to inducing one party to share important information with the other. A familiar example of such a default rule is the foreseeability limitation on consequential damages em-

\footnotetext{
29 An early and clear example of such a mechanism was the common-law seal. A sealed promise was enforceable despite evidence of factors such as fraud or duress. Modern illustrations can be found in the Uniform Commercial Code (for example, expressions such as F.O.B., F.A.S., and "as is") as well as the standard form corporate indenture. See Broad v. Rockwell Intern. Corp., 642 F.2d 929, 943 (5th Cir. 1981) ("uniformity of the indentures that govern competing debenture issues is what makes it possible meaningfully to compare one debenture issue with another'').
} 
bodied in Hadley $v$. Baxendale. ${ }^{30}$ The limitation on the award of damages for unascertainable consequences of breach induces the promisee to disclose to the promisor private information that the promisor may not have concerning the consequences of breach. This information would not be disclosed to the promisor under a full-performance compensation rule. As a result, the benefits from contracting would not be maximized. Thus, the limitation on damages for the unforeseeable consequences of breach increases the efficiency of contracting activity by stimulating the transmission of information between bargainers. ${ }^{31}$

Another example of an information-forcing rule is the implied warranty of fitness for a particular purpose embodied in Article 2 of the Uniform Commercial Code (U.C.C.). This warranty arises whenever a seller of goods has reason to know that his buyer has in mind a particular, noncustomary purpose for the contract goods and that the buyer is relying on the seller's skill and judgment in selecting goods that will fit this particular purpose. The Code's default rule, embodied in U.C.C. § 2-315, forces information in two ways. Initially, the warranty comes into play when the seller knows or has reason to know of the particular needs of the buyer. It therefore gives the buyer with such special needs an incentive to disclose them to the seller in order for the warranty to apply. But once disclosed, the seller is in a position to take steps to protect his position. Where the seller can provide products for the specific purpose, he can supply the needed goods, subject to whatever conditions and limitations are relevant. But where the task is difficult, the seller can insist on the appropriate disclaimers or advise the buyer to look elsewhere.

The information-forcing dimension to certain default rules may explain the general reluctance of common-law courts to grant sellers such as Alcoa relief from unanticipated cost increases under the exculpatory doctrines of commercial frustration and impracticability. ${ }^{32}$ So long as the risk of cost increases owing to low-probability exogenous events rests on the

309 Exch. 341, 156 Eng. Rep. 145 [1854].

${ }^{31}$ Charles J. Goetz \& Robert E. Scott, Enforcing Promises: An Examination of the Basis of Contract, 89 Yale L. J. 1261, 1299-1300 (1980). See also Ayres \& Gertner, supra note 4, at 101-4; William Bishop, The Contract-Tort Boundary and the Economics of Insurance, $12 \mathrm{~J}$. Legal Stud. 241 (1983).

${ }^{32}$ With virtual unanimity, the courts have rejected claims for relief from a contractual obligation that has become more costly than initially anticipated. See, for example, Iowa Elec. Light \& Power Co. v. Atlas Corp., 467 F. Supp. 129, 140 (N.D. Iowa 1978) (52.2 percent cost increase held insufficient to excuse seller's performance), rev'd on other grounds, 603 F.2d 1301 (8th Cir. 1979), cert. denied, 445 U.S. 911 (1980); Publicker Indus. v. Union Carbide Corp., 17 U.C.C. Rep. Serv. 989, 992 (E.D. Pa. 1975) (75 percent cost increase held insufficient to excuse seller); Eastern Airlines, Inc. v. Gulf Oil Corp., 415 F. Supp. 429, 439-42 (S.D. Fla. 1975) (cost increases created by The Organization of Petroleum Exporting Countries and federal controls were reasonably foreseeable). 
seller, the seller has an incentive to design a specialized contractual provision for coping with such "long-tail" contingencies. For example, the seller can bargain for a price ceiling or damage-limitation clause that is automatically triggered whenever unanticipated circumstances increase costs beyond any historical parameters. Neither courts nor legislatures provide parties with any default rules that trigger price ceilings and similar limitation provisions. But by allocating the entire risk to the party who also bears ordinary, foreseeable risks, the courts induce that party to bargain for a risk-sharing arrangement that solves the problem of lowprobability exogenous events.

Moreover, this analysis may also explain why the court in Alcoa was prepared to adjust that contract. Unlike a case where parties have failed to customize the general default rule, the parties in Alcoa clearly believed they had responded to unallocated risk with a sophisticated priceescalation clause. Their mistake was in not anticipating that the particularized alternative might itself fail to operate properly. In such a case, an information-forcing solution, such as the rule that both endogenous and exogenous risks are borne by the performing party, is not likely to motivate further improvements in the customized terms that both parties have agreed on.

The Influence of the Market for Substitute Performance: The Risk of Strategic Behavior. A third function for default rules might be to control the risks of strategic behavior. While the goal is laudatory, implementation may be counterproductive as it is difficult to fashion any default rule that outlines an elaborate contingent set of rights and duties for both parties. Where the default rules are complex, it is difficult to determine who is in breach and who is not. The party, therefore, who resists performance on the ground that his trading partner is in breach may discover to his sorrow that the breach is his own. Having obtained "breacher status," he may now be exposed to damage actions or lose the benefit of valuable contract rights. ${ }^{33}$

Assume, for example, that Alcoa and Essex had written a more complete contract calling for adjustment whenever the price-escalating mechanism failed. If, thereafter, Alcoa were to withhold performance based on a plausible claim for adjustment, it would risk being characterized as a contract breacher. The breacher-status problem gives parties additional incentives to select clear and categorical standards of performance. This problem underscores the advantages of a binary rule, such as a damagelimitation provision, to guard against low-probability events that may have catastrophic effects.

${ }^{33}$ Goetz \& Scott, supra note 9 , at $983-84$. 
But whatever their advantages, simple, all-or-nothing default rules seem to be fundamentally incompatible with the cooperative norm of mutual adjustment. At least in certain contexts, this dilemma is resolved by the presence of a thick market for substitute performance. Where markets for numerous and close substitute performances exist, clear, binary rules tend to dominate flexible and sensitive provisions that require cooperative adjustment. Well-developed markets eliminate much of the need for legally mandated mutual cooperation because parties trading in these markets can often make optimal adjustments unilaterally by, for example, purchasing the necessary adaptation from the lowest bidder on the open market. ${ }^{34}$

But for specialized commercial relationships, such as the Alcoa-Essex contract, the market provides fewer substitutes, and the strategies for maximizing joint benefits obviously become more complex. As specialization increases, each party becomes more vulnerable to strategic demands by the other. The relationship must be maintained in order to exploit the accrued specialization advantages, but the division of the gains must be bargained out in a noncompetitive environment. ${ }^{35}$ In this environment, there is no a priori reason to prefer either clear, binary default rules or a flexible, cooperative rule. A tough default rule-such as the perfecttender rule in sales law-will tend to restrain evasive behavior by the promisor who has come to regret the contract. In contrast, a flexible default rule-such as the doctrine of substantial performance-will deter opportunistic refusals to cooperate by the promisee, who might seize on technical noncompliance with tough performance standards in order to escape an unfavorable contract when the market moves against it. The optimal rule in a world of costly enforcement will depend on which type of strategic behavior is more prevalent in particular cases. Specialized contracting environments thus seem to require more complex and varied

\footnotetext{
${ }^{34}$ This point is well illustrated by the perfect-tender rule embodied in U.C.C. § 2-601. Under the perfect-tender rule, the buyer has no duty to accept the seller's tender of nonconforming goods. The rule gives the buyer a choice: accept the defective tender and recover the reduction in values as damages, or reject the performance and recover market-based damages. The perfect-tender default rule thus reduces the incentive for the buyer to adjust cooperatively once an unanticipated contingency occurs. Conversely, to the extent that the law deviates from the clear default rule of perfect tender by adopting instead a standard of substantial performance, the seller has more opportunity to evade its contractual obligation by claiming that the tendered goods are "just as good" as the contract goods. The choice between a default rule of perfect tender or a rule of substantial performance thus turns on whether we are more concerned with restraining sellers' evasions or encouraging buyers' adjustments. See Robert E. Scott \& Douglas L. Leslie, Contract Law and Theory 599-600 (1988).

${ }^{35}$ Benjamin Klein, Robert G. Crawford, \& Armen A. Alchian, Vertical Integration, Appropriate Rents, and the Competitive Contracting Process, 21 J. Law \& Econ. 297 (1978).
} 
strategies in setting optimal default rules, just as recent commentary, including Gillette's, has recognized.

\section{A Relational Theory: Specifying Default Rules in a Regime of IMPERfEct Legal ENFORCEMENT}

The problem of controlling strategic behavior for complex contracts in thin markets seems at first blush to support the claim of Gillette and others that optimal default rules should be tailored to the preferences and/ or circumstances of particular parties. But before this proposition is adopted as a normative prescription, it might be useful to search for a plausible positive theory of the existing regime of categorical default rules. In short, why are default rules in commercial law framed in terms of generalized, categorical, winner-take-all risk assignments? Consider, for example, the doctrines of perfect tender, mistake, excuse, and breach. These rules assign risks on an all-or-nothing, binary basis. Given the dominating impulse toward mutual adjustment, what explains the wellestablished reluctance of courts and legislatures to impose cooperative adjustments in particular cases?

I do not think that egoism is equal to this task. Instead, I think that the driving force behind the binary character of most commercial-law default rules lies in the inherent limitations of the legal enforcement mechanism, ${ }^{36}$ which is, at best, a blunt instrument to secure cooperative adjustments. We must come to grips with this apparent paradox: in the real world of costly enforcement, legal rules are both a threat and a temptation. Thus, any cooperative default rule that makes one party's duty to cooperate a condition of the other's duty to perform will inevitably invite both cooperative responses from the party subject to legal sanction and evasive responses from the other.

Whenever circumstances call for mutual adjustment, the prospect of legal enforcement provides each commercial party with reciprocal options. ${ }^{37}$ Consider once more Alcoa and Essex. As an obligor, Alcoa can choose to comply voluntarily with its contractual obligation (to deliver the aluminum at the contract price), or it can elect to evade that contractual responsibility through foot dragging or haggling over contract interpretation. Conversely, as an obligee, Essex can select an enforcement strategy that is either flexible or severe. If Essex adopts, and writes into the contract, a flexible strategy that requires a voluntary cooperative adjustment in the price escalator, and if Alcoa complies with its redefined re-

36 The following analysis builds on the discussion in Scott, supra note 17, at 2042-47.

37 John Scholz, Cooperation, Deterrence, and the Ecology of Regulatory Enforcement, 18 L. \& Soc'y Rev. 179 (1984). 
sponsibilities, then both parties benefit from the mutual cooperation. But if Essex adopts a flexible and cooperative enforcement policy, Alcoa (which still faces losses under the contract) is tempted to evade its contractual responsibilities even further, as by claiming that Essex's cooperation was less than it had agreed to undertake. A flexible standard of contractual performance, such as the doctrine of substantial performance, thus reduces both the clarity of the standard and the severity of any subsequent legal enforcement. In turn, it thereby increases the risk of noncooperative evasion by obligors who still regret the ex ante contractual allocation of risk.

The desire to restrain these forms of evasion may explain the law's preference for clear, tough, winner-take-all default rules. These binary rules set the stage for cooperative adjustments that take place on an ongoing, extralegal basis. Within the framework of clear rules, the parties can adopt nonbargained modes of cooperation that survive because of the mutual gains they generate over time. ${ }^{38}$ Indeed, in many settings, either party may be able to induce cooperative behavior at the first interaction by announcing its intention to cooperate conditionally with the other side, or by taking the first cooperative step, with an implicit or explicit tit-fortat threat. ${ }^{39}$ Thereafter, both parties can "lock into" a long-term cooperative equilibrium. ${ }^{40}$ The social forces of reciprocity, ${ }^{41}$ honesty, and solidarity can bond persons to the desired patterns of cooperation, especially in a

38 The experimental results that tend to confirm this observation are reviewed in Stuart Oskamp, Effects of Programmed Strategies on Cooperation in the Prisoner's Dilemma and Other Mixed-Motive Games, 15 J. Conflict Resolution 225, 237-42 (1971).

39 The strategy of tit-for-tat is the simplest of the many responsive strategies to repeated interactions of Prisoner's Dilemma and other strategic interaction games. The considerable experimental research is summarized in R. Downing, The Prisoner's Dilemma Game as a Problem Solving Phenomenon: An Outcome Maximization Interpretation, 6 Simulation and Games 366 (1975); see also Robert Axelrod, Effective Choice in the Prisoner's Dilemma, 24 J. Conflict Resolution, 3, 6-7 (1980) (reporting a computer tournament in which tit-for-tat strategy won iterated Prisoner's Dilemma game).

${ }^{40}$ Warner Wilson, Reciprocation and Other Techniques for Inducing Cooperation in the Prisoner's Dilemma Game, 15 J. Conflict Resolution 167, 186 (1971).

${ }^{41}$ Group-generated norms, individual ethics, and other informal mechanisms play important roles in regulating contractual relations. The pervasive social norm of reciprocity is particularly relevant to contractual interactions. (See A. Gouldner, The Norm of Reciprocity: A Preliminary Statement, 25 Am. Soc. Rev. 161, 172-76 (1960).) These norms support an initial predisposition to cooperate, which is then reinforced by reciprocal interactions. Parties to long-term contracts should be able to announce a precommitment to conditional cooperation and thereby encourage a stable pattern of cooperative adjustment. By the simple expedient of punishing evasion and rewarding cooperative adjustment, a party assuming a leadership role can bring out the best in the other and thereby reinforce a cooperative equilibrium. See Steven J. Brams, Newcomb's Problem and Prisoner's Dilemma, 19 J. Conflict Resolution 596, 603-4 (1975). 
world where there are substantial benefits from good business reputations. $^{42}$

Notwithstanding the force of these extralegal norms, contractual breakdowns will nonetheless occur, especially where the short-term payoffs from defection are substantial. Sometimes, therefore, the parties are likely to demand renegotiation and to back their demands with a threat of suit. The parties, in essence, have learned to behave under two sets of rules: a strict set of rules for legal enforcement and a more flexible set of rules for social enforcement. ${ }^{43}$ It may be that the great lesson for the courts is that any effort to judicialize these social rules will destroy the very informality that makes them so effective in the first instance. It becomes, therefore, critical for courts not to generalize about the power of these informal social sanctions from the legal cases, as these only arise when the social sanctions themselves have broken down. The cases give no clue of the power of these social sanctions in situations where they have carried the parties through hard times. Understood in their broader context, binary legal rules serve as an effective complement to the more flexible means of social adjustment. The efforts by Gillette and others to introduce more particularized default rules into the legal setting may therefore frustrate the social norm of cooperation that they seek to advance.

\section{Conclusion}

A theory of commercial law begins with a model of how commercial parties allocate risk. I have suggested that rational commercial actors will be motivated by a dominating objective: to reduce the risk of those contingencies over which one or the other has some measure of control. This objective will encourage all bargainers, whatever their particular attitudes toward risk, to adjust to future circumstances in order to maximize the expected value of their contract. It follows that individual attitudes toward risk are unlikely to provide very useful evidence of how particular parties would have chosen to allocate unspecified risks.

Even if we abandon the inquiry into individual attitudes toward risk, we are still faced with the vexing challenge of translating the motivation toward cooperative adjustment into legal default rules. The arguments

\footnotetext{
${ }^{42}$ See Robert Ellickson, A Critique of Economic and Sociological Theories of Social Control, 16 J. Legal Stud. 67 (1986).

${ }^{43}$ Macaulay has established that the recurring, conventional problems of maintaining cooperative relations in a business setting are chiefly enforced through nonlegal mechanisms. (See Stewart Macaulay, Non-contractual Relations in Business: A Preliminary Study, 28 Am. Soc. Rev. 55 (1963).)
} 
advanced by Gillette and others support the development of more complex and particularized default rules. In each case, these claims for particularization fail to appreciate the unique role of default rules as part of the broader system for facilitating the contracting activities of commercial parties. I have argued that the underlying objective of commercial law is the development of both generalized default rules and individualized alternatives that together reduce the costs (and errors) of contracting. Each function thus supports a different dimension of the process of contract formation. The inherent tension between majoritarian and individualized conceptions of rational choice, between simple and complex risk-allocation schemes, and between self-interest and cooperation all result from efforts to accommodate these core processes of particularization and generalization. Thus conceived, the independent role of generalized default rules becomes easier to justify. In choosing a general strategy for advancing joint interests, the instinct of the common law has been to adopt clear, categorical standards of performance. This development does not imply either that commercial actors are egoists or that the common-law rules should be amended to require ex post adjustment. Rather, the most convincing explanation for the common-law rules is that they represent only a portion of a larger system of social control that deters large-scale evasion but encourages ongoing patterns of mutual cooperation. A more complete evaluation of the existing scheme of default rules requires, therefore, that we continue to explore the linkages between legal rules and these underlying social norms. 